\title{
STRATEGI PENGEMBANGAN PENYULUHAN PERTANIAN DI KABUPATEN SEMARANG JAWA TENGAH \\ The Development Strategy Of Agricultural Extension In The District Of Semarang Central Java
}

\author{
Bayu Sasongko*), Sriroso Satmoko**), Mukson**) \\ e-mail: bumijo_net@yahoo.com \\ *) Mahasiswa Magister Agribisnis Universitas Diponegoro \\ **) Pengajar Fakultas Peternakan dan Pertanian Universitas Diponegoro
}

\begin{abstract}
This study was aimed to analyze the implementation of agricultural extension in Semarang Regency, analyze the strengths, weaknesses, opportunities and threats of agricultural extension activities in Semarang Regency, also analyze the position and determine the strategy to be implemented in developing agricultural extension in Semarang Regency.

The research used a survey method and located in Semarang Regency, Central Java. This research was conducted in November 2016 to May 2017 using 99 Respondents and 6 people as a key person respondents. Factors affected the development of agricultural extension in Semarang Regency consists of five strengths factors, five weakness factors, five opportunities factors, and five threats factors. Alternative strategies were develop using SWOT analysis and prioritization strategy was determined using AHP (Analytical Hierarchy Process) with expert choice version 11 program.

The result showed that the development strategy of agricultural extension in Semarang Regency using S-O strategy along with priority strategy, namely (1) a proposal to the government for enacted regulations that have a positive impact on farmers with 0,299 in value, in the form of government regulations to give agriculture product price assurance, (2) Optimizing the performance of extension workers to conduct a training to the farmers by approaching farmer groups with 0,245 in value, could be conducted by technical inventiveness extension in district level, visitation and supervision, farmer discussion in district level, and farmers field day, (3) Utilizing the community positive perception to optimize the performance of agricultural extension with 0,156 in value, through the certification of agricultural extension as a formal recognition to competent counselor in their duties, (4) Conduct a training and extension activities to improve farmers skills and knowledge with 0,150 in value, through training and visitation approach, (5) Utilizing technology innovations development to optimize the role and function of the extension services in each region with 0,150 in value by means of agricultural technology dissemination produced by the Research and Development of the Ministry of Agriculture.
\end{abstract}

Keywords: Strategy, Counseling, Strength, Weakness, Opportunities, Threats

\begin{abstract}
ABSTRAK
Penelitian ini bertujuan untuk menganalisis pelaksanaan penyuluhan pertanian di Kabupaten Semarang, menganalisis kekuatan, kelemahan, peluang, dan ancaman kegiatan penyuluhan pertanian di Kabupaten Semarang, menganalisis posisi dan menentukan
\end{abstract}


strategi yang akan diterapkan dalam mengembangkan penyuluhan pertanian di Kabupaten Semarang.

Metode penelitian yang digunakan adalah metode survei. Lokasi penelitian berada di Kabupaten Semarang Jawa Tengah. Penelitian ini dilakukan pada bulan November 2016 sampai dengan Mei 2017. Responden Penyuluh Pertanian sebanyak 99 orang, dan key person sebanyak 6 orang. Faktor pengembangan penyuluhan pertanian di Kabupaten Semarang meliputi 5 faktor kekuatan, 5 faktor kelemahan, 5 faktor peluang, dan 5 faktor ancaman. Dianalisis menggunakan analisis SWOT, dan penentuan prioritas strategi menggunakan AHP (Analytical Hierarchy Process) dengan program expert choice versi 11 .

Hasil penelitian menunjukkan strategi pengembangan penyuluhan pertanian di Kabupaten Semarang menggunakan strategi S-O dengan prioritas strategi yaitu (1) Melakukan usulan kepada pemerintah untuk menerbitkan peraturan yang berdampak positif terhadap petani dengan nilai 0,299 , berupa peraturan pemerintah yang memberikan jaminan harga terhadap produk pertanian, (2) Mengoptimalkan kinerja penyuluh untuk melakukan pembinaan kepada petani melalui pendekatan kelompok tani dengan nilai 0,245 , dilakukan dengan cara temu teknis penyuluhan tingkat kecamatan, kunjungan dan supervisi, rembug tani tingkat kecamatan dan hari temu lapang petani (farmers field day), (3) Memanfaatkan persepsi positif masyarakat untuk mengoptimalkan kinerja penyuluh dengan nilai 0,156 , melalui sertifikasi penyuluh pertanian sebagai pengakuan formal seorang penyuluh kompeten dalam menjalankan tugasnya, (4) Melakukan kegiatan pelatihan dan penyuluhan untuk meningkatkan keterampilan dan pengetahuan petani dengan nilai 0,150, melalui pendekatan latihan dan kunjungan, (5) Memanfaatkan perkembangan inovasi teknologi untuk mengoptimalkan peran dan fungsi lembaga penyuluhan disetiap wilayah dengan nilai 0,150 , melalui diseminasi teknologi pertanian yang dihasilkan oleh Badan Penelitian dan Pengembangan Pertanian Kementerian Pertanian.

Kata kunci: Strategi, Penyuluhan, Strength, Weakness, Opportunities, Threats

\section{PENDAHULUAN}

Penyuluhan

pertanian adalah pendidikan nonformal yang ditujukan kepada petani dan keluarganya dengan tujuan jangka pendek untuk mengubah perilaku termasuk sikap, tindakan dan pengetahuan ke arah yang lebih baik, serta tujuan jangka panjang untuk meningkatkan kesejahteraan masyarakat Indonesia. Kegiatan penyuluhan pertanian melibatkan dua kelompok yang aktif, yaitu kelompok penyuluh dan kelompok yang disuluh (petani dan keluarganya) (Sastraatmadja, 1993).

Kabupaten Semarang sebagai salah satu Kabupaten di Provinsi Jawa Tengah (Data BPS tahun 2015) mempunyai luas lahan 95.020,67 ha yang terdiri dari: lahan pertanian sawah $23.919,51$ ha $(25,17 \%)$, lahan pertanian bukan sawah 36.360,07 ha $(38,27 \%)$, lahan bukan pertanian 34.741,09 ha $(36,56 \%)$. Luasnya lahan pertanian di Kabupaten Semarang tentunya membutuhkan tenaga penyuluh pertanian yang profesional, sistem penyelenggaraan penyuluhan yang benar, metode penyuluhan yang tepat, serta manajemen penyuluhan yang baik supaya proses penyelengaraan penyuluhan pertanian dapat berjalan dengan baik.

Penyuluhan yang berorientasi produksi ternyata tidak serta merta diikuti dengan meningkatnya pendapatan dan kesejahteraan petani, tidak sekaligus memberdayakan petani. Hal ini karena penyuluh terlalu fokus pada peningkatan 
produksi komoditas semata akan tetapi tidak terfokus pada petani dan keluarganya. Oleh karena itu diperlukan pengkajian terhadap strategi pengembangan penyuluhan pertanian yang dapat diterapkan di Kabupaten Semarang sesuai dengan tujuan utama penyuluhan pertanian yaitu untuk meningkatkan kesejahteraan petani.

Berdasarkan latar belakang tersebut dapat dirumuskan permasalahan sebagai berikut:

1. Bagaimana kekuatan, kelemahan serta peluang, ancaman dalam mengembangkan penyuluhan pertanian di Kabupaten Semarang.

2. Bagaimana posisi dan strategi prioritas yang akan diterapkan dalam mengembangkan penyuluhan pertanian di Kabupaten Semarang.

Tujuan penelitian ini adalah:

1. Menganalisis kekuatan, kelemahan serta peluang, ancaman kegiatan penyuluhan pertanian di Kabupaten Semarang .

2. Menganalisis posisi dan menentukan strategi prioritas yang akan diterapkan dalam mengembangkan penyuluhan pertanian di Kabupaten Semarang.

\section{METODE PENELITIAN}

Penelitian ini menggunakan metode deskriptif kuantitatif dengan pendekatan survei. Obyek dari penelitian ini adalah Penyuluh Pertanian PNS, THL-TBPP dan Penyuluh Swadaya di Kabupaten Semarang. Lokasi penelitian dipilih secara sengaja (purposive) yaitu di Kabupaten Semarang. Pertimbangan penentuan lokasi adalah wilayah Kabupaten Semarang sebagian besar merupakan lahan pertanian yang penduduknya bekerja pada sektor pertanian, sebagai petani penggarap maupun pemilik lahan. Pengambilan sampel dalam penelitian ini mengunakan purposive sampling (pertimbangan).
Penentuan jumlah sampel pada setiap kecamatan didasarkan pada potensi dibidang pertanian dan jumlah kelompok tani binaan para penyuluh yang mengacu pada Peraturan Menteri Pertanian 82 Tahun 2013 tentang pedoman pembinaan kelompok tani dan gabungan kelompok tani bahwa setiap penyuluh pertanian dapat membina 8-16 kelompok tani. Data yang dikumpulkan dalam penelitian ini meliputi data primer dan sekunder. Data primer diperoleh melalui pengamatan langsung atau observasi, FGD (Focus Group Discussion), dan survai (kuisioner). Data sekunder diperoleh melalui kajian pustaka dan literatur untuk menunjang landasan teori yang berhubungan dengan penelitian.

Teknik pengolahan data dan analisis dalam penelitian ini menggunakan teknik uji validitas, reliabilitas, analisis SWOT dan AHP. Faktor-faktor strategis pengembangan penyuluhan pertanian di Kabupaten Semarang (kekuatan, kelemahan, peluang dan ancaman) dianalisis dengan analisis situasi yaitu analisis SWOT. Penentuan prioritas strategi dalam pengembangan penyuluhan pertanian di Kabupaten Semarang digunakan analisis AHP (Analytical Hierarchy Process) dengan alat bantu program Expert Choice.

\section{PEMBAHASAN}

\section{Uji Validitas dan Reliabilitas}

Berdasarkan hasil uji validitas variabel kekuatan, kelemahan, peluang, dan ancaman terhadap strategi pengembangan penyuluhan di Kabupaten Semarang dengan taraf signifikan $(\alpha) 5 \%$ menunjukkan bahwa nilai r-hitung lebih besar dari r-tabel $(0,700)$ sehingga seluruh instrumen penelitian dinyatakan valid.

Berdasarkan hasil uji reabilitas variabel kekuatan, kelemahan, peluang, dan ancaman terhadap strategi pengembangan penyuluhan di Kabupaten Semarang dengan 
tingkat kepercayaan $(\alpha) 5 \%$ menunjukkan bahwa nilai koefisien reabilitas (r) lebih besar dari 0,6 sehingga seluruh instrumen penelitian dinyatakan reliabel.

\section{Analisis SWOT (Strength, Weakness, Opportunity, Threat)}

Hasil identifikasi lingkungan internal Penyuluhan Kabupaten Semarang diperoleh 5 (lima) faktor kekuatan (strength) dan 5 (lima) faktor kelemahan (weakness) sebagai berikut:

Tabel 1. Matrik IFAS (Internal Factor Analysis Summary)

\begin{tabular}{|c|c|c|c|c|}
\hline \multicolumn{2}{|r|}{ Faktor - faktor Strategi Internal } & Bobot & Rating & Skor \\
\hline \multicolumn{5}{|c|}{ Kekuatan (strenght) } \\
\hline 1 & Peraturan pemerintah yang mendukung penyuluhan & 0,11 & 3,28 & 0,361 \\
\hline 2 & Alokasi pendanaan penyuluhan yang memadai & 0,10 & 3,09 & 0,309 \\
\hline 3 & Tingkat pendidikan SDM penyuluh yang tinggi & 0,10 & 2,96 & 0,296 \\
\hline 4 & Pengalaman kerja SDM penyuluh yang memadahi & 0,11 & 3,14 & 0,345 \\
\hline \multirow[t]{2}{*}{5} & Memiliki kelembagaan penyuluhan sampai tingkat kecamatan & 0,10 & 3,13 & 0,313 \\
\hline & Total & $\mathbf{0 , 5 2}$ & & 1,624 \\
\hline \multicolumn{5}{|c|}{ Kelemahan (weakness) } \\
\hline 1 & Peraturan pemerintah yang saling bertentangan & 0,10 & 3,23 & 0,323 \\
\hline 2 & $\begin{array}{l}\text { Pelaksanaan tugas yang tidak sesuai dengan tugas pokok dan fungsi } \\
\text { penyuluh }\end{array}$ & 0,10 & 3,17 & 0,317 \\
\hline 3 & Keterampilan SDM relatif rendah & 0,09 & 2,83 & 0,255 \\
\hline 4 & Kegiatan pelatihan SDM terbatas & 0,10 & 3,15 & 0,315 \\
\hline \multirow[t]{3}{*}{5} & $\begin{array}{l}\text { Tidak semua balai penyuluhan memiliki sarana dan prasarana } \\
\text { lengkap }\end{array}$ & 0,09 & 2,98 & 0,268 \\
\hline & Total & 0,48 & & 1,478 \\
\hline & & $\mathbf{1 , 0 0}$ & & $\mathbf{0 , 1 4 6}$ \\
\hline
\end{tabular}

Hasil analisis internal menunjukkan bahwa bobot skor untuk faktor kekuatan 1,624 dan faktor kelemahan 1,478, diperoleh selisih 0,146. Secara internal kondisi penyuluhan pertanian di Kabupaten Semarang memiliki kekuatan yang lebih besar dibandingkan dengan kelemahannya.
Artinya bahwa kondisi internal penyuluhan pertanian di Kabupaten Semarang berada pada kondisi yang baik.

Hasil identifikasi faktor eksternal diperoleh 5 (lima) faktor peluang (opportunity) dan 5 (lima) faktor ancaman (threat) sebagai berikut:

Tabel 2. Matrik EFAS (Eksternal Factor Analysis Summary)

\begin{tabular}{|l|l|c|c|c|}
\hline Faktor - Faktor Strategi Eksternal & Bobot & Rating & Skor \\
\hline Peluang (Opportunity) & & & \\
\hline 1 & Sebagian besar masyarakat berprofesi sebagai petani & 0,10 & 3,40 & 0,297 \\
\hline 2 & Sebagian besar usia petani dalam kategori produktif & 0,10 & 3,23 & 0,355 \\
\hline 3 & Sebagian besar petani sudah tergabung dalam kelompok tani & 0,10 & 3,48 & 0,304 \\
\hline 4 & Persepsi positif masyarakat terhadap kegiatan penyuluhan & 0,09 & 3,13 & 0,307 \\
\hline 5 & Inovasi teknologi pertanian terus berkembang $\quad$ Total & 0,10 & 3,15 & 0,312 \\
\hline$\quad$ Ancaman (Threat) & 0,51 & & 1,575 \\
\hline 1 & Alih fungsi lahan pertanian menjadi industri & & & \\
\hline 2 & Regenerasi penyuluh pertanian lambat & 0,09 & 2,35 & 0,212 \\
\hline 3 & Perubahan gaya hidup masyarakat modern & 0,10 & 2,77 & 0,277 \\
\hline
\end{tabular}




\begin{tabular}{|l|l|c|c|c|}
\hline \multicolumn{2}{|l|}{ Faktor - Faktor Strategi Eksternal } & Bobot & Rating & Skor \\
\hline 4 & Sebagian besar petani masih menganut sistem konvensional & 0,10 & 2,06 & 0,306 \\
\hline 5 & Sebagian besar petani masih gagap teknologi & 0,10 & 2,66 & 0,266 \\
\hline & Total & 0,49 & & 1,356 \\
\hline & $\mathbf{1 , 0}$ & & $\mathbf{0 , 2 5 2}$ \\
\hline
\end{tabular}

Hasil analisis eksternal menunjukkan bahwa faktor peluang memiliki total skor 1,575 dan faktor ancaman memiliki total skor 1,356 dengan selisih sebesar 0,252. Penyuluhan pertanian di Kabupaten Semarang memiliki peluang yang lebih baik dibandingkan dengan ancamannya yang berarti penyuluhan pertanian di Kabupaten Semarang dalam merespon faktor eksternal sudah cukup baik.

\section{Matrik Internal dan Eksternal (I-E)}

Berdasarkan nilai skor faktor-faktor internal dan eksternal Penyuluhan
Kabupaten Semarang, maka dapat dibuat diagram matrik I-E yaitu dengan menjumlahkan total skor internal dan eksternal kemudian dihitung selisihnya, menghitung selisih nilai faktor ini dilakukan dengan cara mengurangi total skor kekuatan dan kelemahan, serta faktor peluang dikurangi total skor faktor ancaman. Skor pada diagram matrik I-E dapat dilihat pada Tabel 3.

Tabel 3. Pembobotan untuk diagram SWOT faktor Internal dan Eksternal

\begin{tabular}{|c|c|c|c|c|}
\hline \multirow{2}{*}{ Uraian } & \multicolumn{2}{|c|}{ Faktor Internal } & \multicolumn{2}{c|}{ Faktor Eksternal } \\
\cline { 2 - 5 } & Kekuatan & Kelemahan & Peluang & Ancaman \\
\hline Bobot x rating & 1,624 & 1,478 & 1,608 & 1,356 \\
\hline Selisih & \multicolumn{2}{|c|}{$+0,146$} & \multicolumn{2}{c|}{$+0,252$} \\
\hline
\end{tabular}

Setelah diperoleh angka dari selisih faktor internal dan faktor eksternal, maka dapat dibuat diagram matriks I-E seperti ditunjukan pada Gambar 1. Berdasarkan diagram matriks I-E tersebut, Penyuluhan Kabupaten Semarang terletak pada kuadran I (stability), yang berarti bahwa Penyuluhan Kabupaten Semarang memiliki kekuatan dan peluang yang besar tetapi juga menghadapi beberapa kelemahan dan ancaman. Dengan demikian, strategi yang dapat diterapkan dalam kondisi ini adalah strategi S-O yaitu memanfaatkan kekuatan dan peluang yang ada untuk mengatasi kelemahan dan ancaman dalam pengembangan Penyuluhan Kabupaten Semarang kedepan.

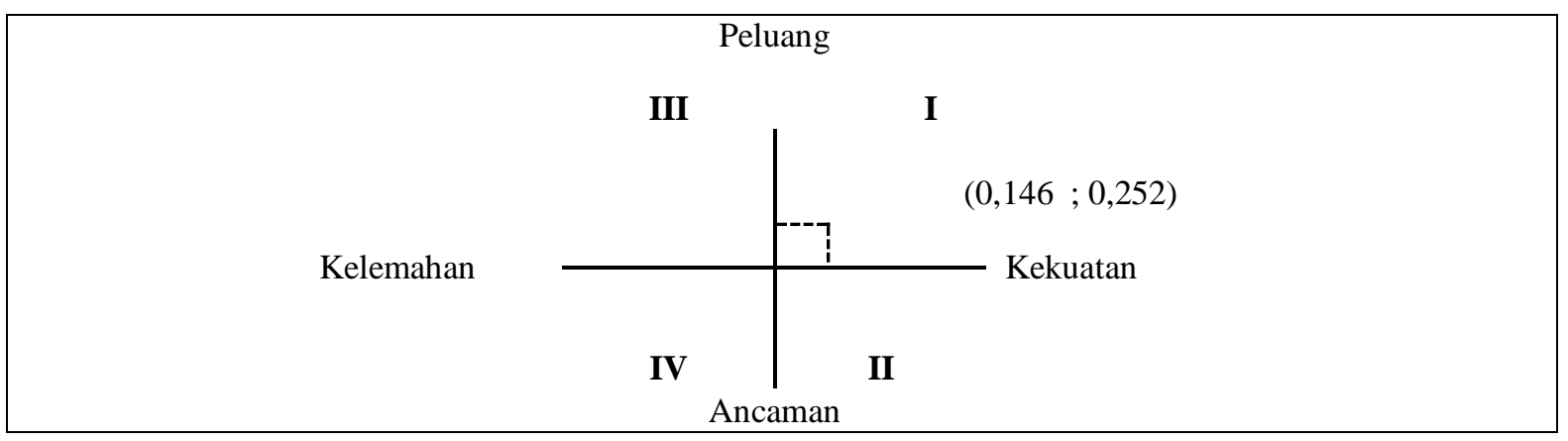

Gambar 1. Diagram Matrik I-E 


\section{Matrik SWOT}

Analisis matrik SWOT Penyuluhan Kabupaten Semarang berdasarkan asumsi bahwa suatu strategi yang efektif akan memaksimalkan kekuatan dan peluang dan meminimalkan kelemahan dan ancaman. Strategi utama yang dapat disarankan yaitu: strategi SO, ST, WO,WT. Analisis ini menggunakan data yang diperoleh dari matrik IFAS dan EFAS sebagai berikut:

Tabel4. Alternatif Strategi Strength - Opportunity (SO) Penyuluhan Pertanian di Kabupaten Semarang

\begin{tabular}{|c|c|}
\hline SWOT & $\begin{array}{l}\text { Kekuatan (Strength) } \\
\text { 1. Peraturan pemerintah yang mendukung } \\
\text { penyuluhan } \\
\text { 2. Alokasi pendanaan penyuluhan yang } \\
\text { memadai } \\
\text { 3. Tingkat pendidikan SDM penyuluh yang } \\
\text { tinggi } \\
\text { 4. Pengalaman kerja SDM penyuluh yang } \\
\text { memadai } \\
\text { 5. Memiliki kelembagaan penyuluhan sampai } \\
\text { tingkat kecamatan }\end{array}$ \\
\hline $\begin{array}{l}\text { Peluang (Opportunity) } \\
\text { 1. Sebagian besar masyarakat berprofesi } \\
\text { sebagai petani } \\
\text { 2. Sebagian besar usia petani dalam } \\
\text { kategori produktif } \\
\text { 3. Sebagian besar petani sudah tergabung } \\
\text { dalam kelompok tani } \\
\text { 4. Persepsi positif masyarakat terhadap } \\
\text { kegiatan penyuluhan } \\
\text { 5. Inovasi teknologi pertanian terus } \\
\text { berkembang }\end{array}$ & $\begin{array}{l}\text { Strategi (SO) } \\
\text { Menggunakan Kekuatan untuk memanfaatkan } \\
\text { peluang }\end{array}$ \\
\hline
\end{tabular}

Analisis AHP (Analytical Hierarchy penyuluhan pertanian di Kabupaten Process). Semarang. Hasil rumusan alternatif strategi Analisis AHP (Analytical Hierarchy pengembangan penyuluhan pertanian di Process) digunakan untuk menentukan Kabupaten Semarang adalah sebagai prioritas strategi dalam pengembangan berikut: 


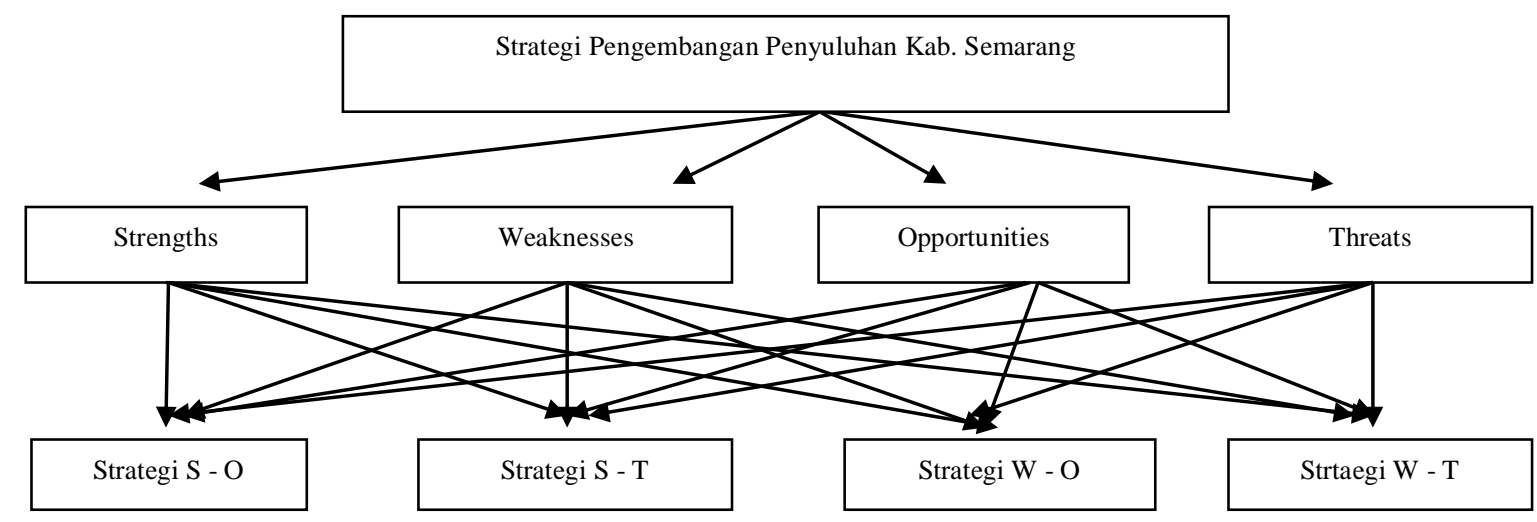

Gambar 2. Rumusan Alternatif Strategi

Hasil kuesioner dari orang kunci (key person) dianalisis menggunakan program Ekspert Choice versi 11 untuk mengetahui tingkat skala prioritas alternatif yang ada.

Nilai Inconsistency Ratio $\leq 0,1$ berarti keputusan yang diambil oleh responden key person dalam menentukan skala prioritas telah konsisten. Semakin kecil nilai Inconsistency Ratio maka semakin konsisten responden dalam menentukan skala prioritas.

Tabel 5. Hasil Analisis Kriteria Strategi Pengembangan Penyuluhan Pertanian di Kabupaten Semarang

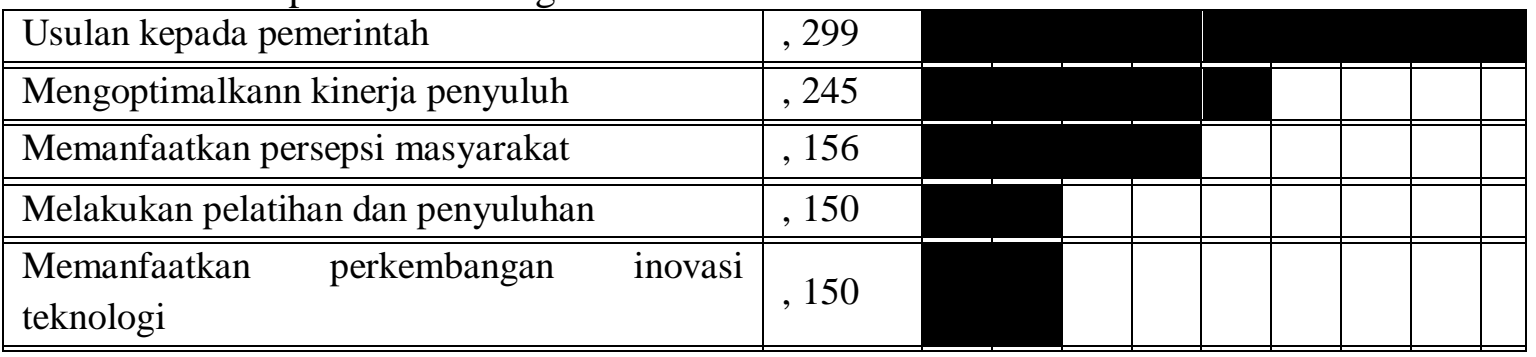

Inconsistency Ratio $=0,08$

Berdasarkan Tabel 5 dapat diketahui bahwa skala prioritas dari kelima strategi yang dapat digunakan untuk mengembangkan penyuluhan pertanian di Kabupaten semarang adalah sebagai berikut:

1. Melakukan usulan kepada pemerintah untuk menerbitkan peraturan yang berdampak positif terhadap petani dengan nilai 0,299 , berupa peraturan pemerintah yang memberikan jaminan harga terhadap produk pertanian. Berdasarkan hasil penelitian Mantau (2010) dikemukakan bahwa peran pemerintah dalam menentukan harga pangan non beras sangat diperlukan, terutama untuk mencegah permainan harga oleh para pedagang, yang bukan saja merugikan petani sebagai produsen tetapi juga masyarakat sebagai konsumen. Hal tersebut bukan hanya berdampak pada tingkat kesejahteraan petani, tetapi bisa lebih luas dan dapat mengancam ketahanan pangan karena ketidakstabilan harga pangan menyebabkan daya beli konsumen menurun sehingga dapat memicu terjadinya krisis pangan. Dampak yang lebih jauh dari 
fenomena tersebut adalah terjadinya inflasi. Lebih lanjut Ilham (2006) menyatakan bahwa kebijakan harga pangan sangat mempengaruhi ketersediaan pangan, terutama kebijakan harga output. Namun demikian untuk lebih mengefektifkan kebijakan harga pangan ini perlu didukung oleh kebijakan lain, terutama yang berkaitan dengan kebijakan penyediaan infrastruktur dan penelitian yang sifatnya jangka panjang. Kebijakan output, terutama dalam bentuk kebijakan harga dasar yang dilakukan selama ini perlu dijaga efektivitasnya untuk lebih merangsang petani tetap berproduksi. Namun agar pangan yang tersedia dapat diakses oleh segala lapisan masyarakat, terutama kelompok berpendapatan rendah, maka kebijakan harga atap perlu juga dilakukan. Dengan dua kebijakan ini diharapkan konsumen dan produsen pangan saling diuntungkan.

2. Mengoptimalkan kinerja penyuluh untuk melakukan pembinaan kepada petani melalui pendekatan kelompok tani dengan nilai 0,245 , dilakukan dengan cara temu teknis penyuluhan tingkat kecamatan, kunjungan dan supervisi, rembug tani tingkat kecamatan dan hari temu lapang petani (farmers field day), berupa pertemuan antara petani, penyuluh, dan dinas instansi terkait untuk saling tukar menukar informasi untuk meyebarluaskan hasil demonstrasi usaha tani yang dihasilkan serta umpan baliknya. Ardita (2017) menyatakan bahwa metode penyuluhan kelompok/meeting merupakan yang paling menonjol dalam pengetahuan dan keterampilan metode penyuluhan, hal ini dikarenakan penyuluh lebih sering melakukan penyuluhan kelompok yang merupakan pertemuan rutin kepada kelompok tani atau gabungan kelompok tani.

3. Memanfaatkan persepsi positif masyarakat untuk mengoptimalkan kinerja penyuluh dengan nilai 0,156 , yaitu melalui sertifikasi penyuluh pertanian sebagai pengakuan formal seorang penyuluh kompeten dalam menjalankan tugasnya. Zulfikar (2018) menyatakan bahwa persepsi petani terhadap kompetensi penyuluh pertanian tanaman pangan yang meliputi: penyusunan program dan programa, penyiapan materi, pemilihan media dan penerapan metode berkategori sedang. Lebih lanjut Herbenu (2007) menyatakan bahwa kinerja penyuluh pertanian yang memenuhi standar penugasan sangat diperlukan untuk mencapai tujuan pembangunan pertanian. Kinerja penyuluh pertanian merupakan hasil kerja yang dicapai sesuai tugas dan tanggung jawab yang dilaksanakan, secara efektif dan efisien berdasarkan kemampuan, pengalaman serta penggunaan waktu.

4. Melakukan kegiatan pelatihan dan penyuluhan untuk meningkatkan keterampilan dan pengetahuan petani dengan nilai 0,150 , dilakukan dengan pendekatan latihan dan kujungan yaitu pendekatan penyuluhan yang memadukan pelatihan bagi penyuluh sebagai upaya meningkatkan kemampuan penyuluh dalam melaksanakan tugasnya, yang ditindaklanjuti dengan kunjungan kepada petani/kelompok tani yang dilakukan secara terjadwal dan 
terukur. Sungkawa (2015) menyatakan bahwa terdapat hubungan erat antara metode kerja latihan dan kunjungan (Laku) dengan keberhasilan penerapan teknologi PTT padi sawah.

5. Memanfaatkan perkembangan inovasi tekhnologi untuk mengoptimalkan peran dan fungsi lembaga penyuluhan disetiap wilayah dengan nilai 0,150 , dengan cara diseminasi teknologi pertanian yang dihasilkan oleh Badan Penelitian dan Pengembangan Pertanian Kementerian Pertanian. Harahap (2016) menyatakann bahwa dengan penguasaan informasi dan teknologi oleh penyuluh maka penyuluh akan mampu memberikan bimbingan kepada petani sesuai dengan teknologi yang dibutuhkan petani.

\section{KESIMPULAN}

Berdasarkan hasil penelitian dan pembahasan dapat disimpulkan sebagai berikut:

1. Analisis SWOT dihasilkan 5 (lima) faktor kekuatan dengan 2 (dua) skor tertinggi yaitu peraturan pemerintah yang mendukung penyuluhan dengan skor 0,361 dan pengalaman kerja SDM penyuluh yang memadai dengan skor $0,345,5$ (lima) faktor kelemahan dengan 2 (dua) skor tertinggi yaitu peraturan pemerintah yang saling bertentangan dengan skor 0,323 dan pelaksanaan tugas yang tidak sesuai dengan tugas pokok dan fungsi penyuluhan dengan skor 0,317 , 5 (lima) faktor peluang dengan 2 (dua) skor tertinggi yaitu sebagian petani dalam katagori produktif dengan skor 0,355 dan inovasi teknologi pertanian terus berkembang dengan skor 0,312, dan 5 (lima) faktor ancaman dengan 2 (dua) skor tertinggi yaitu sebagian petani masih menganut sistem konvensional dengan skor 0,306 dan perubahan gaya hidup masyarakat modern dengan skor 0,295.

2. Penyuluhan pertanian di Kabupaten Semarang terletak pada kuadran I, yaitu strategi SO dengan proiritas strategi yaitu: (1) Melakukan usulan kepada pemerintah untuk menerbitkan peraturan yang berdampak positif terhadap petani dengan nilai 0,299, berupa peraturan pemerintah yang memberikan jaminan harga terhadap produk pertanian, (2) Mengoptimalkan kinerja penyuluh untuk melakukan pembinaan kepada petani melalui pendekatan kelompok tani dengan nilai 0,245 , dilakukan dengan cara temu teknis penyuluhan tingkat kecamatan, kunjungan dan supervisi, rembug tani tingkat kecamatan dan hari temu lapang petani (farmers field day), (3) Memanfaatkan persepsi positif masyarakat untuk mengoptimalkan kinerja penyuluh dengan nilai 0,156 , yaitu melalui sertifikasi penyuluh pertanian sebagai pengakuan formal seorang penyuluh kompeten dalam menjalankan tugasnya, (4) Melakukan kegiatan pelatihan dan penyuluhan untuk meningkatkan keterampilan dan pengetahuan petani dengan nilai 0,150 , melalui pendekatan latihan dan kunjungan, (5) Memanfaatkan perkembangan inovasi teknologi untuk mengoptimalkan peran dan fungsi lembaga penyuluhan disetiap wilayah dengan nilai 0,150 , melalui diseminasi teknologi pertanian yang dihasilkan oleh Badan Penelitian dan 
Pengembangan

Pertanian

Kementerian Pertanian.

\section{SARAN}

Beberapa hal yang dapat disarankan terkait dengan strategi pengembangan penyuluhan di Kabupaten Semarang antara lain:

1. Keberpihakan semua pihak (Pemerintah, Petani, Penyuluh, dan Swasta) dalam kegiatan penyuluhan.

2. Menumbuhkan kesadaran petani untuk bergabung dalam kelompok tani.

3. Memberikan peluang dan kesempatan pada penyuluh pertanian untuk mengikuti pelatihan dalam rangka peningkatan kinerja.

4. Mendorong penyuluh pertanian untuk mengikuti sertifikasi penyuluh sekaligus diberikan tunjangan sertifikasi.

5. Pemanfaatan media internet untuk mengakses perkembangan inovasi teknologi menjadi kebutuhan para penyuluh dalam kegiatan penyuluhan.

\section{REFERENSI.}

Ardita, Suci. D. W. P. dan D. Widjanarko. 2017. Kinerja Penyuluh Pertanian Menurut Persepsi Petani: Studi Kasus di Kabupaten Landak. Journal of Vocational and Career Educational. 2 (1): 1-8.

Badan Pusat Statistik Kabupaten Semarang. 2015. Kabupaten Semarang Dalam Angka Tahun 2015, Semarang: Badan Pusat Statistik.

Departemen Pertanian. 2013. Permentan No. 82 Tahun 2013 Tentang Pedoman Pembinaan Kelompoktani dan Gabungan Kelompoktani, Jakarta.

Harahap, N, W. Harjono, K. Tarigan. 2016. Kaji Model Metode Penyuluhan di Era Berlakunya Asean Economic Community (AEC) Melalui Sistim Penyuluhan yang Bersinergi, Terintegrasi, dan Berkelanjutan. Jurnal Agrica Extensia. 10 (1): 1122.

Herbenu, P. C. 2007. Pengembangan Sumberdaya Petugas Penyuluh Lapangan PPL Pertanian Guna Menghadapi Persaingan dan Meraih Peluang Kerja. Jurnal Ilmu-Ilmu Pertanian. 3(1): 1-1.

Ilham, N., H. Siregar dan Priyarsono. 2006. Efektivitas Kebijakan Harga Pangan Terhadap Ketahanan Pangan. Jurnal Agro Ekonomi. 24 (2): 157-177.

Mantau, Z. dan Bahtiar. 2010. Kajian Kebijakan Harga Pangan Non Beras Dalam Kontek Ketahanan Pangan Nasional. Jurnal Litbang Pertanian. 29 (2): 58-65.

Sastraatmadja, Entang. 1993. Penyuluhan Pertanian: Falsafah, Masalah dan Strategi.Penerbit Alumni. Bandung.

Sungkawa, I., A. Jaeroni, Y dan A. Prahatsi. 2015. Hubungan Metode Pelatihan dan Kunjungan (Laku) Penyuluh Pertanian Lapangan dengan Penerapan Teknologi Pengelolaan Tanaman Terpadu (PTT) Padi Sawah. Jurnal Agrijati. 28 (1): 68-78.

Zulfikar, S. Amanah dan P. S. Asngari. 2018. Persepsi Petani terhadap Kompetensi Penyuluh Pertanian Tanaman Pangan di Kabupaten Aceh Utara. Jurnal Penyuluhan. 14 (1): 159-174. 